\title{
EchoGéo
}

40 | 2017

Ressources urbaines (2)

\section{Three scientific legacies and one new research perspective}

Conclusion to the special issue on urban resources

\section{Monique Bertrand}

\section{OpenEdition}

\section{Journals}

Electronic version

URL: https://journals.openedition.org/echogeo/15130

DOI: $10.4000 /$ echogeo.15130

ISSN: 1963-1197

Publisher

Pôle de recherche pour l'organisation et la diffusion de l'information géographique (CNRS UMR 8586)

\section{Electronic reference}

Monique Bertrand, "Three scientific legacies and one new research perspective", EchoGéo [Online], 40 | 2017, Online since 30 June 2017, connection on 10 August 2021. URL: http://

journals.openedition.org/echogeo/15130 ; DOI: https://doi.org/10.4000/echogeo.15130

This text was automatically generated on 10 August 2021

EchoGéo est mis à disposition selon les termes de la licence Creative Commons Attribution - Pas

d'Utilisation Commerciale - Pas de Modification 4.0 International (CC BY-NC-ND) 


\section{Three scientific legacies and one new research perspective}

Conclusion to the special issue on urban resources

Monique Bertrand

1 I would like to thank the editorial team of EchoGéo, as well as the editors of this comprehensive issue on urban resources, for granting me a few pages for this conclusion. Adding to the ten contributions presented in this double issue was an exciting opportunity. It would however have been difficult to add more arguments to the general introduction, or to supplement articles that retrace a deep reflexive path: this issue draws from the very core of a coherent and expansive field of research around the notion of resources, with its related urban forms and cognitive issues. Therefore, I prefer to provide an overview of the various elements of scientific heritage that may have, directly or indirectly, inspired some of these contributions as well as the conversations they sparked during our seminar "Ressources urbaines et droit à la ville" ("Urban resources and the right to the city") organized by Labex Dynamite ${ }^{1}$.

2 The title "Reading socio-spatial inequality" immediately suggests the scientific objective addressed through the question of urban resources, both from the perspective of cities and from that of their inhabitants. However, the aim was not just to qualify places and distances, to illustrate gaps in consumption patterns and practices, and to measure spatial discriminations that create tension within cities, based on a broad definition of the players involved. Additionally, this issue also set itself the challenges of stressing the benefits of field investigation, of referring to a research methodology and of highlighting a number of survey variables.

Such comparisons between data production techniques do indeed contribute significantly to the current interest in the conditions of access to the city. Beyond the discrepancies observed according to usual socio-economic nomenclatures, and beyond living standard indicators, analyses tend to edge towards the same interpretation of urban metabolism that the Chicago School had attempted to describe over a century ago. Ultimately, it needs to be reminded that the workers, residents, urban service users and neighbors, including when transient and neglected by public policies, are the 
prime actors in the making of the city - those that give the city its intimate pulse. These people evidence the existence of "place effects", which need to be interpreted on every scale in the organization of urban spaces.

4 In my opinion, the analytical potential of the notion of resources derives from three scientific milestones. These were set in contexts that geographers have long associated with development studies: countries and cities that experienced extreme population redistribution and fast territorial transformations. When dealing with these cities, a handful of clichés on the planet of slums and the resilience of the informal sector divert us from examining the global production of vulnerability and its local differentiation. We should therefore acknowledge the important contribution made by studies on the "Global South", as they discuss diverse forms of mobility, thereby enabling new international comparisons between economically diverse areas with poor levels of political regulation.

\section{The urban inclusion of migrants}

5 In many respects, this issue is reminiscent of the body of scholarship on population displacement from rural to urban areas. This theme is not just a reminiscence from the seventies: today, as the largest cities and the strongest rates of urban growth are found in the South, this line of enquiry on living conditions in cities continues to track new migratory routes, including international ones, as well as more recent migratory flows - some of which settle at the margins, for instance in the periphery of Mexico, while others are overlaid on established channels as in the case of the Sao Paulo metropolitan center.

6 An abundant literature analyzes the stories of people settling into cities and adapting to the evolutions of the job and housing markets, echoing other literary and cinematographic accounts. These approaches set an important landmark in the study of urban phenomena, at a time when cities still accounted for a minority within national demographies, or were mostly significant in terms of net migration. This literature is not drying out today as large cities have become conurbations, generating complex flows beyond those described as "rural exodus", and new places of insertion beyond traditional central and peripheral areas. Today, these cities' demographic growth appears to rely more significantly on the natural population growth contributed by rural migrants' children, and on the internal redistribution processes associated with urban sprawl. The city's inward pull is giving way to outward reterritorialization processes, with new entrants settling in the peripheries.

7 In the last scientific generation, the term "insertion" (translator's note: insertion in French) was never innocent. Although this word has today become too loaded with overtones to account for a complex reality, at the time in France, it provided an alternative from the word "integration" (translator's note: intégration in French), which implied that urban "foreigners" were expected to give up their original characteristics - similarly, according to the terms of migration policies, migrants were expected to forcibly "assimilate" to the host national culture. The concept of insertion then became more flexible, and began to refer both to connections to and departures from individuals' initial conditions and characteristics. This shift was accompanied by a number of indicators: biographic "trajectories" (trajectoires), sociability and support "channels" (filières), "networks" (réseaux) of connections through which newcomers are 
directed to already settled compatriots and to other circles of belonging. These keywords are quite naturally present in Laurent Faret's and Sylvain Souchaud's articles. Addressing legal vulnerability and the need to tackle the global reorganization of industrial activity, these contributions reflect a degree of social involvement in migration. Both consider the historical dimension of migration, with an analysis that embraces the timescale of generational renewal alongside that of individual life cycles. While the issue of "insertion" remains difficult to translate - especially in English these analyses add to the numerous studies on the transmission of empty housing, economic niches and the culture of poverty, to quote Oscar Lewis' observations on 1960s Mexico. We could look for instance at the wealth of anthropological studies of the Zongo Muslim communities in Western Africa spanning over two decades, or at the many sociological monographs examining specific population groups in their respective urban settlements: these studies either observe a grouping of migrants among themselves, or show how communities soon dissolve into diverse neighborhoods and mixed working conditions. Such observations of the city first focus on the satisfaction of basic economic needs, before moving on to examine the meaning that arises from these new people and connections, giving rise to a new type of urban identity. Somewhere in between the notion of cultural loss, as per Philip Meyer's 1961 account of mining towns in Austral Africa where "tribesmen" become "townsmen", and the restrictive attributes of the uprooted lumpenproletariat: one first key to understanding urban resources lies in the part played in migrants' path, whatever the level of autonomy they eventually acquire, by the "opportunities" they grabbed locally to enter the job and housing markets and work their way up.

Geographic analysis draws upon this rich scholarly material. From the perspective of a migration specialist who approaches metropolitan reality through the trajectories some of them chaotic - of specific national groups, the last people to arrive in a context of political tightening or economic redeployment still remain the "entrepreneurs" of their own mobility. The most basic forms of urban subsistence can become resources that serve a migratory project, helping tackle external obstacles. Diverted from transitory purposes, they can be converted to suit the needs of an individual's stay in the city, creating a new field of possibilities: the city can also be an improvised station before the journey reaches its intended destination, a re-routing or the result of a setback.

10 As for urban studies, they face an analytical bifurcation when examining the places shaped by migratory flows in the city. According to some studies, people who are originally labeled as "migrants" inevitably end up thinking of themselves as citydwellers. New forms of investigation thus consider their project as one of an urban rather than migratory nature: people are more concerned with finding an optimal location in the city than with identifying new living horizons; they become "experts" on the means of achieving these aims and of avoiding the risks attached to large conurbations; or they might engage in female empowerment processes. This is exactly what happens in Rio's favelas, as documented by Rafael Soares Gonçalves' study: the comparison gradually stirs free from the opposition between migrants and nonmigrants, or between domestic and international migrants. The analysis can also highlight the specificities of each regional origin, as is the case with Sylvain Souchaud's study of garment factories, in order to differentiate between migrants from one same location according to other criteria: newcomers versus early arrivers, workshop owners 
versus manual laborers, homeowners versus people living in their place of work. But other studies mostly place the focus on location, including places of arrival and dispatch, rather than on specific population groups. In this perspective, understanding a city's structuring by successive generations of immigrants requires regularly updating housing typologies: this is what Vincent Berdoulay and Thi Thu Trang Ngo undertake with the periphery of Hô Chi Minh City. This also requires making comparisons between neighborhoods according to their demographic mix. While origin-related variables remain decisive, their combined effects become more tightly interwoven as time goes.

11 The first option for tracking migrants is that adopted by Antonine Ribardière and Aurélia Michel's contributions, looking at trajectories from the Mexican state of Oaxaca to the industrial municipality of Naucalpan in the state of Mexico. These articles show the importance of complementing statistical census data with qualitative data from surveys targeting women, including workingwomen and housewives. Working from the characteristics of their place of origin, the study goes on to investigate individual and family trajectories, that act both as determinants and differentiators in the choice of domestic work and rented housing; or how migrants assess their urban environment through to a set of practical skills, which depend on the challenges faced by each specific population group.

12 The second option, which consists in monitoring a specific neighborhood, is best illustrated by Jean-François Valette's paper which brings a conclusive contribution to the observations of the Mexican capital delivered in this issue: the city is not seen as a backdrop, as a final stop or as a discrete presence, but rather as a complex metropolitan unit. In his article's title, Valette uses the singular "quartier", or "neighborhood" (L'ancrage au quotidien dans les colonies populaires de la périphérie de Mexico: une approche par les pratiques et les ressources du quartier / Everyday integration in Mexico City's peripheral low-income settlements: neighborhood-based practices and resources). However, his study of the peripheral low-income settlements reveals the city's demographic gigantism and multi-generational layering. The settlements start off as pioneer fronts making the most of local assets to access housing stock; they are then formalized, offering a pool of local services, even when the area's diverse population commutes out to work in other urban areas. The main difference between settlements appears to be the intensity and directions of their connections with the rest of the city. Ultimately, the key issue is not so much the migrants' insertion but rather a neighborhood's integration to the rest of the city.

\section{The longitudinal paradigm}

13 The analytical shift from migration trajectories to residential reorganization, and from life stories to urban history, appears in another family of thought around the notion of urban resources: these focus on the concrete effects of time on urban practices, attempting to measure their scope over different timescales by borrowing from longitudinal methods. This heritage is not just methodological: it is also epistemological or "paradigmatic", to quote the words of Daniel Courgeau who delineated a living space within successive and simultaneous places, showing how the individual experiences measured by demographics echo other social experiences observed by different disciplines. 

account for data that was produced in retrospect according to a comprehensive biographical calendar, or to complement a long-term observation of one given population cohort. While Jean-François Valette follows one same sample of population through several successive statistical sources going back as far as 2007, he considers low-income settlements as "individuals" that grow their population and socioeconomic fabric over the course of their urban history.

Some articles do however stress the contribution made by longitudinal studies of migration and urban insertion, in particular when studying urban organization from the perspective of housing: residential mobility, demand for new urban services, employment-related negotiation within households, or family participation to childcare. These studies highlight the roles played by other forms of metropolitan travel, the efforts deployed by city-dwellers in their home-to-work commute and in accessing other urban resources, and the risk of social relegation that occurs when there is a mismatch between one's residential map and employment map. Explicit references are made to this type of analysis - whether to explain how certain formats were adopted for a ground survey, or to justify the analysis of specific "choices" and "arbitrations".

One first source of inspiration resides in describing the density and diversity of urban experiences, using material that is more reliable than aggregated second-hand data whose sources might be too old, poorly designed or biased to answer the questions asked. Scholars may for instance consider a case of "urban integration", with the perspective required of any study of an individual's experience: spanning from the premigration period to the acquisition of a stable accommodation, to show how one asset brings another. In any case, an individual's understanding of the city expands over time, and becomes fragmented according to the various spatial scales of observation. These conditions are necessary to analyze variations in individual behaviors. To draw a basic comparison, this idea was already suggested by Oscar Lewis when he reconstructed the biography of tenancies in the center of Mexico City. On the scale of a family, the experience of the city appears different between newcomers and their children, between male and female siblings, and between children who temporarily moved away from the city and others who failed to extract themselves from their working-class background.

17 A few years later, in the Ivory Coast, Philippe Haeringer $(1972,1983)$ created "a biographic interview and synoptic transcription model", comparing various migratory journeys of the 1970s and focusing for instance on "three city-dwellers, every day, (...) in the competition of Abidjan". This method was based on the serial application of one same information framework. Haeringer stirred clear from family-centered investigation to instead present three parallel narratives capturing the stories of three unrelated migrants: their training, work and succession of employment and joblessness periods; their individual emancipation leading to the creation of a new domestic entity; and finally, their housing history retraced through a succession of migratory stages and urban places of residence. Throughout this chronological course, similarities in migrants' origins, stopovers and destinations showed a consistency between these people's trajectories and motivations, rather than being the result of existing connections between the migrants at the time of the survey. 

from demographic questionnaires using the "triple B" model or comparing several cohorts, and formalizing the study of biographic calendars. For instance, the studies examining "Three generations of city-dwellers in Sahel" (Trois générations de citadins au Sahel) delivered by Philippe Antoine and the INED working group on biographical approaches analyzed "events" (événements), "stays" (séjours) and "states" (états) of life, both in and of themselves and as milestones in an individual's "career" (carrières) and "curriculum" (cursus). The responses collected from both individuals and large samples reflect all three aspects - matrimonial, professional and residential - of one same life, which can be more or less predetermined, chaotic or open to genuine freedom of action. within an individual's progression and in relation with others and with an everevolving context. This approach is also relevant to the cities examined in this issue, which have undergone a drastic restructuring in the last decades. It can help qualify a migrant's choices as a factor of upward or downward mobility, and understand each trajectory as ascension or as a block. The observation of interactions between different calendars raises the same qualitative questions that were asked about smaller samples: in the other areas of urban life, what are the effects of normative social stages such as reaching adult age? What are those of accidental occurrences such as marriage breakdown or long-term unemployment? What are the consequences of changed circumstances such as those introduced by the structural adjustment programs in developing countries? For instance, in the case of Santiago de Chili described by Claudia Arellano Yévenes and Fernando Saavedra Peláez, the creation of the Transantiago has transformed the local technical and management context, causing the other modes of transportation to reposition themselves within the metropolitan area. Similarly, in the case of Cape Town as described by Solène Baffi, the end of apartheid and the rise of metropolitan governance led to the promotion of combined transport practices, which calls for a reinterpretation of the scope of urban segregation.

Regardless of the methodological format adopted, a longitudinal approach places the focus on the notion of choice. Choices are reflected by a change in an individual's state - that is, by an outcome rather than by an intention. Rather than being the product of an individual's rational plan, based on a pure cost calculation within a free market economy, choice is defined as an ongoing experience and an interaction with others, which makes it possible to move beyond methodological individualism. This approach seems essential in a field where possibilities are built by collective practices, and are the product of constraints and anticipation at a given time in an individual's life, in a specific social circle and within a specific context.

21 In the continuum formed by the analysis of modern life, mobility takes on a whole new significance: the aim is not only to describe what happens after migration - new moves, stabilization or residential captivity -, but also to understand the interconnection of living spaces within a city. Urban mobility is not just a way of satisfying incompressible needs and accessing new resources, but also a resource per se, the object of strategies and dreams of a better life. In this perspective, transportation choices are comparable with migratory decisions and residential options: they highlight a decision-making process, which can occur by default - "I have no choice" is a frequent answer among the persons surveyed - but is often the result of an arbitration that was made over a 
period of time, in reaction to a pool of collectively built possibilities. An illustration of this idea can be found in Kouakou Konan's paper, looking at informality and accident hazard in Bouaké. In the few texts dedicated to urban travel, the focus shifted from the scale of a lifetime to that of shorter sequences of weekly and everyday routine. Ultimately, these two perspectives draw from the same semantics: two-sided "opportunities" (opportunités) - immediate returns vs. negative externalities -, alternatives occurring over a given timescale, "portfolios" (portefeuilles) of options and "directories" (repertoires) of local information. Images and cost-distance-time calculations are associated with various places in the city, revealing other discrepancies based on financial means, social capital and gender.

This longitudinal approach therefore complements the analysis of the job and housing markets with an analysis of urban mobility, which has in itself become a commodity. Beyond physical infrastructure and management models, unequal access to resources also reflects other characteristics of urban life, thus supporting an organic and relational understanding of urban resources. In one article, the analysis focuses on the distance between urban peripheries and economic centers: two-wheel transport in Santiago shows a differentiation between "new" and "traditional" cyclists, where the former are socially successful while the latter cycle for lack of an alternative. Similarly, the integration of black suburbs into the territorial redeployment of post-apartheid cities remains problematic due to radial public transport networks. In other cases, illustrated by Aurélia Michel or Vincent Berdoulay and Thi Thu Tran Ngo, the allocation of male and female roles in families and the management of domestic time provides a better understanding of decision-making mechanisms.

Ultimately, geography has shifted its objectives in comparing neighborhoods: in addition to topological and demographic criteria, which can make an area more attractive to some populations or turn it into a launching pad to new resources for others, the analysis now includes a place's relational qualities and the intensity of the movements that connects it to the city as a whole, linking it to other places that are perceived as strong or weak.

\section{Capabilities, accessibility, urban policies}

With the neoliberal wave of the 1980s, the collapse of the welfare state and the austerity policies have had a deep impact on cities around the world: their public services and facilities have been re-evaluated according to criteria of cost-effectiveness and commercial competitiveness. Water sanitation, waste collection, water supply and energy are increasingly becoming inequality issues. These need to be tackled all the more that they interfere with other issues such as access to healthcare and education, which now fall within the human development index. Urban resources are thus replacing employment and housing as measures of a city's attractiveness, and as indicators of the perpetuation, intensification or transformation of socio-economic inequality. They also reflect to which extent the overall growth of consumer needs has created new forms of vulnerability and new poverty traps in cities. Southern cities are examined through the prism of poverty rather than through that of migration. The poor are viewed alternatively as the "social side effects" of the lost decade of development and of the public debt crisis, and as indicators of the new adaptive resources offered by the informal sector. Rafael Soares Gonçalves' account of the 
favelas reflects this understanding by capturing a double dependency: towards water supply companies and towards local resources, even when those are characterized by a history of insecure land tenure. Many informal economic sectors continue to exist even when residents rally urban planning programs.

Anti-poverty and pro-poor investment policies implemented after this major turning point have important methodological implications. When it came to concretely evaluating these policies' effects in terms of improvement, measures of livelihood ${ }^{2}$ underwent a complete methodological overhaul, with large-scale surveys commissioned to monitor the living standard and its variations. Rather than weighing the average "shopping basket" based on household income, the surveys measured the various types of consumption. These surveys introduced the notions of recourse and capacity, and legitimated these policies' liberal bias by recommending to "include the poor into the market". Similarly, in many surveys supported by the World Bank, the provision of services is questioned from the joint criteria of capacity and willingness to pay.

This evolution shows the influence of agent-based decision models, and more broadly of freedom of choice understood as capabilities by Amartya Sen, based on a broad definition of monetary, social and spatial resources. This issue does in a way contribute to this shift, by placing the focus on accessibility: not just because the local provision of services and the territorial impact of infrastructure have always been of interest to geography, but also because any form of mobility aimed at reaching physical facilities and networks, regardless of its intrinsic characteristics, is now understood as a social skill and a capacity to make use of urban information. This creates a distinction between migrants with poor educational capital versus others, first-time buyers versus other residents, females versus males, etc.

In this sense, a scientific perspective on inequality of access increasingly involves a political approach. It requires considering a broad spectrum of practices, such as securing land tenure and preserving environmental resources; and investigating choices that may be unstable, or forms of switching between solutions: public or private, formal or informal, legal or clandestine, etc. This type of analysis covers legal frameworks as well as the power play and negotiations that surround urban facilities throughout the lifespan of public policies, targeted projects and incentives to improve governance. Researchers also witnessed the rise of "inclusion for all" policies in cities, which aim not only to complement, update and restore facilities, but also to ensure equal access for all potential users and in particular better access for some specific groups, as well as increasing "positive freedoms" by considering the value added to some goods and services.

28 According to this last school of thought, the notion of resources can be augmented with new observations and typologies - showing how migrants and residents might attempt, to a varying extent, to leverage policies in order to bring about broader consultation mechanisms or have an influence on the management of cities: actions include claims for rights and legitimacy, community-led movements, backdoor negotiations, episodic protests or frontal resistance, or a "choice" between late reactions or anticipation... These various actions can confirm a groups' lack of visibility and another groups' empowerment. Comparison is once again necessary when considering wide ranges of actions with potential/unused solutions, including forms of inhibition, political double game, occasional participation, networked advocacy... This angle was explored during 
the seminar of October 2015, whose title covered both the notion of resources and that of the "right to the city".

Beyond this slogan borrowed from Henri Lefebvre's book title and often quoted in international circles, it would be worth analyzing the political resources drawn upon by city-dwellers to tackle changes in their living environment. Although such practices are often observed by political sociology in Northern cities and associated with notions of participation and citizenship, they are not so present in this issue: while focusing on the spatial dimension of inequality, the authors do not document the strategies aimed at seizing opportunities to address this inequality. Only Laurent Faret and Rafael Soares Gonçalves refer to the not-for-profit sector and to civil society organizations working to support the rights of clandestine migrants by directing them to legal or housing services, and to reassess the needs of the favelas in comparison with those of other legal neighborhoods.

An analysis of "bottom-up" politics could thus contribute to the study of the notion of urban resources, at a time when the growing claims to rights are likely to bring this notion to the debate on political subjectivation. But first and foremost, which resources should we focus on? Which rights should be given a practical priority? Equitable access to water? Rent control? The survival of ambulant traders? The end of transport monopolies? Free healthcare? Expanded school choice? Local occurrences are raising a number of alternatives: social rights or human rights? Sector rights or universal rights? Our fields of inquiry appear increasingly open. However, what periods of action should we consider? What leadership history? What activism trajectories, where relevant? This field of analysis could also lend itself to a revision of methodologies and concepts inherited from past schools of thought.

This special issue is an attempt at augmenting the notion of resources, while opening up scope for new fields of inquiry. Some contributions highlight the experiences of migrants and others those of female city-dwellers. Some look at characteristic neighborhoods, while others focus on connections within the city. In all these cases, the analysis starts from residential practices, localized on a fine scale, to reach beyond a vision of the city's construction and governance as seen through the sole perspectives of a few "stakeholders". From this study of modest players and ordinary practices, we build indicators of economic status, but also an appreciation of sociability models, cultural standards, cognitive strategies and, ultimately, political meaning. In acknowledging the universality of these processes over three continents, and in highlighting original local responses to a broad spectrum of individual, social and contextual challenges, this double issue well and truly lives up to its objectives.

\section{BIBLIOGRAPHY}

Antoine Ph. (ed.), Ouédraogo D. (ed.), Piché V. (ed.), Diop A.B. (préf.), 1998. Trois générations de citadins au Sahel : trente ans d'histoire sociale à Dakar et à Bamako. Paris, L'Harmattan, $283 \mathrm{p}$. 
Courgeau D., 1975. Le concept de migration. In Institut National de la Statistique et de la Démographie (ed.), Actes du quatrième colloque de démographie africaine : migrations, état-civil, recensements administratifs, p. 27-37.

Courgeau D., 2002. Évolution ou révolutions dans la pensée démographique ?. Mathématiques et sciences humaines, $\mathrm{n}^{\circ} 160$, p. 49-76.

GRAB, 2009. Biographies d'enquêtes. Bilan de 14 collectes biographiques. Paris, INED Méthodes et savoirs, $\mathrm{n}^{\circ}$ 3, IRD, RSEH, $340 \mathrm{p}$.

Haeringer Ph, 1972. Méthodes de recherche sur les migrations africaines : un modèle d'interview biographique et sa transcription synoptique. Cahiers de l'ORSTOM, série Sciences humaines, vol. IX-4.

Haeringer Ph, 1983. Trois citadins jour après jour : un Ebrié, un Baoulé et un Mossi dans la compétition abidjanaise. Cahiers de l'ORSTOM, série Sciences humaines, vol 19-4.

Lefebvre H., 1967. Le droit à la ville. L'Homme et la société, nº 6, p. 29-35.

Lewis O., 1978 (trad. rééd.). Les enfants de Sanchez. Autobiographie d'une famille mexicaine. Paris, Gallimard, 644 p.

Mayer Ph., 1961. Townsmen or Tribesmen: Conservatism and the Process of Urbanization in a South African City (Contributions by Iona Mayer). Capetown, South African, Oxford University Press Rhodes University, 306 p.

Sen A., 2012 (trad. réed.). Éthique et économie. Paris, Puf, 372 p.

\section{NOTES}

1. Seminar of October 15th 2015 at Université de Paris Diderot, under the direction of Aurélia Michel and Antonine Ribardière, "Dynamique Territoriales et Spatiales" laboratory (LabEx), working group 2.4.: "Produire la ville 'ordinaire"' ("Making the 'ordinary' city).

2. Many development projects were restructured around livelihood funds.

\section{INDEX}

Subjects: Sur le Champ - Sur le Terrain

\section{AUTHOR}

\section{MONIQUE BERTRAND}

Monique Bertrand, monique.bertrand@ird.fr, is a Research Director at the Institut de Recherche pour le Développement (Development Research Institute) and a member of the CESSMA research unit (Centre for Social Science Studies on Africa, the Americas and Asia, UMR 245 IRD). 